\title{
柱の圧縮試験における荷重偏心と初期たわみの分離・決定についで
}

\author{
林 \\ 毅**，小林昭***

\section{On the Determination of Load Eccentricity and Initial \\ Deviation in the Column Compressive Tests}

Tsuyoshi HAYASHI* and Akira KOBAYASHI

\begin{abstract}
The load eccentricity and the initial column deviation from straightness are quite different in nature, and they are to be determined separately for the rigorous analysis concerning the column compressive characteristics. Only the initial deviation is considered heretofore. The present work is to report the experimental determination of both quantities. In the following procedure, the experimental determination is made for the aluminum alloy bars to be found the minor magnitude of load eccentricity, say, less than 10 $\%$ of that of initial deviation in most cases.
\end{abstract}

\section{記号}

\begin{tabular}{|c|c|}
\hline$A$ & 断面欀 \\
\hline$a_{0}$ & 初期たわみの最大值 \\
\hline$C_{1}, C$ & 中立軸と最遠ファイバーとの距離 \\
\hline$e$ & 荷重偏心 \\
\hline$E I$ & 柱の曲げ焩性 \\
\hline$h$ & 柱の断面の高さ \\
\hline$L$ & 柱の長さ \\
\hline$n_{E}$ & $P / P_{E}$ \\
\hline$P$ & 作用する軸王維荷重 \\
\hline$P_{E}$ & オイラー座屈荷重 \\
\hline$w_{0}$ & 初期たわみ \\
\hline$w_{a}$ & 付加たわみ \\
\hline$w$ & 全たわみ \\
\hline$\lambda$ & 定数 \\
\hline$\varepsilon$ & 歪み \\
\hline$\delta_{0}$ & (最大初期たわみ量)/(杜の断面の半高さ) \\
\hline
\end{tabular}

\section{1. 序論}

元来，荷重偏心は通常，試䤅片の両端の単純支持条 件を出来るだけよく保つために装着するナイフ・エッ 泣状キャップの出来具合や，それへの試駼片端末部 の, はめ込み程度に起团する. 他方, 試験柱の初期た

*昭和 41 年7月8日原腢要理

** 東京大学工学部航空粪科

*** 凍京大娄字宙航空研究所树料部
わみは試験片製作過程て入ってくる.両者は性質上全 く別個のものでっって試験ごとに，また，試験片ごと に翼なるであろう，精密な杜の正繀特性を調べるため には、これらの罴を別々に分離し決定することが必要 となる，何故ならば，与えられな試娩機では圾駼片装 着後の特性はこれらの量によってほとんど支配される からである.これまで荷重偏心の量は無視して初期 たわみのみを取り上げて夷験的に決定しているが゙， 本研究は荷重偏心と初期たわみの両者を実驗的に決定 する一つの方法の提案である.

荷重がオイラー荷重に近つくと，杜のたわる特性は 正弦波状に近づくのて、ここては実験によるたわみお よび歪みの湖定値を整理する一つの間単化として，た わみ形を正弦半波項て近似したまま，荷重漏心の量 は一定とし，ダイヤル・ゲージおよび昰みダージによ る测定値を用いて決定する方法を考察した。

\section{2. 解桥理論}

2.1. 简単化した解析理論 簡単化するためにつぎ の仮定をおく、(第1図)

（1）杜の断面は一様て両端て単純支持される.

（2）桂㣖同一侧に等しい量の荷重偏心を有しここ の量は荷重に無関係とする.これを相当荷重猵 心量eとあらわす。

（3）杜の初期たわみは正弦半波とする*.

$$
w_{0}=a_{0} \sin \frac{\pi x}{L}
$$

軸荷重Pをうける柱の蔽たわみ

$$
E I\left(w^{\prime \prime}-w_{0}{ }^{\prime \prime}\right)=-P(w+e)
$$

となり，これを両端ての境界条件

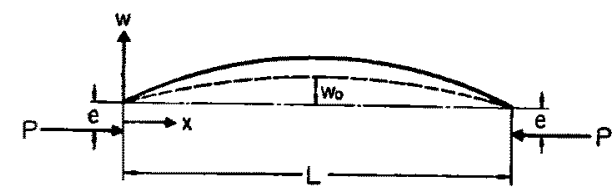

第1区偏心荷重をうける初期たわみを有する柱

*付然 1. 照のこと。 
$x=0$ および $x=L$ て $w=0$ および $w^{\prime \prime}=-P_{\ell} / E I$

の下て解くと，

$$
w(x)=\frac{a_{0}}{1-n_{E}} \sin \frac{\pi x}{L}+e F(x)
$$

を得る.ここに，

$$
\begin{aligned}
P_{E} & =\frac{\pi^{2} E I}{L^{2}}=\text { オイラー座屈荷重 } \\
F(x) & =\frac{\cos \left[\lambda L\left(1-\left(\frac{2 \pi}{L}\right)\right]\right.}{\cos \lambda L}-1 \\
\lambda & =\frac{\pi}{2 L} \sqrt{n_{E}}
\end{aligned}
$$

である・

荷重Pによる付加たわみ $w_{a}(x)$ は，

$$
\begin{aligned}
w_{a}(x)= & w(x)-w_{0}(x)=a_{0} \frac{n_{E}}{1-n_{E}} \sin \frac{\pi x}{L} \\
& +e F(x)
\end{aligned}
$$

と表わされる.（6）式は付加たわみ $w_{a}$ を種々の荷重 值Pで測定すれば原理的には 90 と $e$ か分離・決定さ れることを示している，例えば $x=L / 2$ をとると，

$$
w_{a}\left(\frac{L}{2}\right)=k_{1} a_{0}+k_{2} e
$$

となる、ただし

$$
k_{1}=\frac{n_{E}}{1-n_{E}}, \quad k_{2}=\sec \left(\frac{\pi}{2} \sqrt{n_{E}}\right)-1
$$

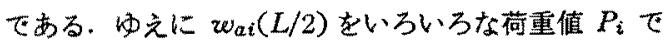
洌定すれば最小二乗法によって

$$
\sum_{i=1}^{n}\left[k_{1}\left(P_{i}\right) \cdot a_{0}+k_{2}\left(P_{i}\right) \cdot e-w a_{i}\left(\frac{L}{2}\right)\right]^{2}=\min .
$$

が $a_{0}$ とcが決定出来る2). しかし, 差 $\left(k_{2}-k_{1}\right)$ が $n_{E}$ 加増加してもそれはど大きくならないために，P と $w_{a}$ の測定精度を高めないと， $a_{0}$ と $e$ を実駼て精 度よく求めることが出来ない。

\begin{tabular}{l|l|l}
\multicolumn{2}{c|}{ 第 1 表 } & $k_{1}, k_{2}$ \\
\hline$n_{E}$ & $k_{1}$ & $n_{E}$ \\
\hline 0 & 0 & 0 \\
0.25 & 0.333 & 0.414 \\
0.50 & 1.000 & 1.260 \\
0.75 & 3.000 & 3.810 \\
1.00 & $\infty$ & $\infty$ \\
\hline
\end{tabular}

柱の表面ての歪みについては， $x$ 断面の凸側に生ず る王縮歪みを $\varepsilon_{1}$, 凹側のそれを $\varepsilon_{2}$ とすると，

$$
\begin{aligned}
& \varepsilon_{1}=\frac{P}{E A}-\frac{P C_{1}}{E I}\left(k_{8} a_{0}+k_{4} e\right) \\
& \varepsilon_{2}=\frac{P}{E A}+\frac{P C_{2}}{E I}\left(k_{3} a_{0}+k_{4} e\right)
\end{aligned}
$$

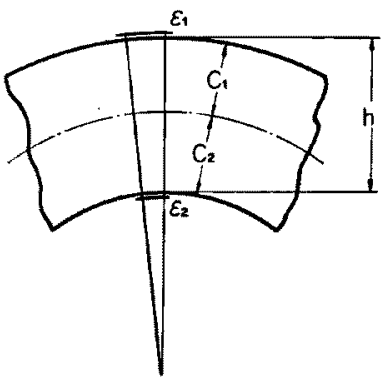

第2図 柱表面に生ずる歪

となる、ここに、

$$
k_{3}=\frac{1}{1-n_{E}} \sin \frac{\pi x}{L} \text { およ゙ } k_{s}=F(x)+1
$$

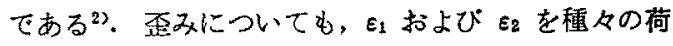
重 $P$ で測定すれば原理的には $a_{0}$ と $e$ が求められるこ とになる。

再び $x=L / 2$ を測定個所にとると，

$$
k_{3}=\frac{1}{1-n_{E}} \text { およよひ } k_{4}=\sec \left(\frac{\pi}{2} \sqrt{n_{E}}\right)
$$

となるから，(10）式は,

$$
\begin{aligned}
\varepsilon_{1}= & \frac{\pi^{2} I}{A L^{2}} n_{E}-\frac{\pi^{2} C_{1} h}{L^{2}} n_{E}\left[\frac{a_{0} / h}{1-n_{E}}\right. \\
& \left.+\frac{e}{h} \sec \left(\frac{\pi}{2} \sqrt{n_{E}}\right)\right] \\
\varepsilon_{2}= & \frac{\pi^{2} I}{A L^{2}} n_{E}+\frac{\pi^{2} C_{2} h}{L^{2}} n_{E}\left[\frac{a_{0} / h}{1-n_{E}}\right. \\
& \left.+\frac{e}{h} \sec \left(\frac{\pi}{2} \sqrt{n_{E}}\right)\right]
\end{aligned}
$$

となり,さらに書き直すと，

$$
\begin{gathered}
\frac{a_{0}}{h}+\frac{e}{h}\left(1-n_{E}\right) \sec \left(\frac{\pi}{2} \sqrt{n_{E}}\right) \\
=\frac{L^{2}}{\pi^{2} h^{2}} \frac{1}{n_{E}}\left(1-n_{E}\right)\left(\varepsilon_{2}-\varepsilon_{1}\right)
\end{gathered}
$$

を得る.したがって (14) 式において種々の荷重Pて

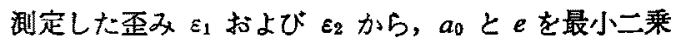
法により決定出来る.

\section{2. 一般的な船析理論一般的な場合として第 3} 図に示されるような，荷重偏心量恃柱の両端でそれぞ れ暴なっている場合を考える．ただし荷重に対しては

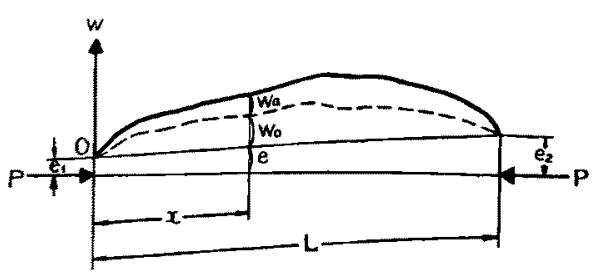

第3图一般的な偏心荷重をろける 初期だるを有する柱 


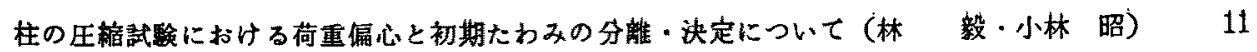

無関倸に一定とする.

杜の初期たわみは，

$$
w_{0}=\sum_{n=1}^{m} a_{n} \sin \frac{n \pi x}{L}
$$

$x$ における荷重偏心は，

$$
e(x)=e_{1}+\frac{e_{2}-e_{1}}{L} x
$$

でえられる．前述と同様に

$$
E I\left(w^{\prime \prime}-w_{0}^{\prime \prime}\right)=-P(w+e)
$$

境界条件は

$$
\left.\begin{array}{l}
x=0: \quad w=0 \text { および } w^{\prime \prime}=-\frac{P e_{1}}{E I} \\
x=L: \quad w=0 \text { および } w^{\prime \prime}=-\frac{P e_{2}}{E I}
\end{array}\right\}
$$

付加たわみ $w_{a}$ は（17）式を（18）式の下で解くこと により，

$$
\begin{aligned}
w_{a}(x)= & w(x)-w_{0}(x) \\
= & \left(\frac{e_{2}}{\sin 2 \lambda L}-e_{1} \cot 2 \lambda L\right) \sin 2 \lambda x \\
& +e_{1} \cos 2 \lambda x-\left(e_{1}+\frac{e_{2}-e_{1}}{L} x\right) \\
& +\sum_{n=1}^{m} a_{n} \frac{P / P_{E n}}{1-P_{P_{n}}} \sin \frac{n \pi x}{L}
\end{aligned}
$$

だだし。

$$
P_{E n}=-\frac{n^{2} \pi^{2} E I}{L^{2}}=n^{2} P_{E}, \quad \lambda L=\frac{\pi}{2} \sqrt{n E}
$$

今， $x=L / 2$ では付加たわみ $w_{\alpha}(L / 2)$ は，

$$
\begin{aligned}
w_{a}(L / 2)= & e_{1}\left(\cos \lambda L-\cot 2 \lambda L \sin \lambda L-\frac{1}{2}\right) \\
& +e_{2}\left(\frac{\sin \lambda L_{L}}{\sin 2 \lambda L}-\frac{1}{2}\right)+a_{1} \frac{n_{E}}{1-n_{E}} \\
& -a_{3} \frac{n_{E}}{9-n_{E}}+a_{5} \frac{n_{E}}{25-n_{E}}+\cdots
\end{aligned}
$$

となる. 同粎に他の点での $w_{a}(x)$ む測定出来るから， 各荷重に対するこれらの $w_{a}(x)$ の同時測定によって, $e_{1}, e_{2}, a_{1}, a_{2}, a_{3} ， \cdots$ を決定することか出来る.ささらに 歪みについても同様に报える.むちろん歪みとたわる の測定值を併用することも出来る.

\section{3. 実験による決定}

実験による決定に打いては，前述の 2.1 による初期

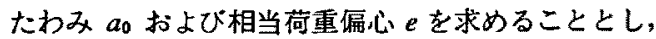
さらに最小二乗法による際の测定諸量の精度の問題斿 よび，たわみを正弦半波1項のみて近似していること を考虑して，(7) 式扣よび（14）式を用い， $n_{E} か ゙ 1$

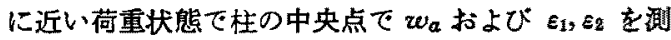
定して $a_{0}$ と $e$ を決定した，実駼に当たっては，deadweight 利用の lever 式軸圧縮䒾置を用い，たわみは
ダイヤル・ゲージにより，また，試片中央での凹凸両

\begin{tabular}{|c|c|c|c|c|c|c|}
\hline No. & $\varepsilon_{2}-\varepsilon_{1}$ & {$\left[\begin{array}{c}w_{a}\left(\frac{L}{2}\right) \\
(\mathrm{mm})\end{array}\right.$} & $a_{0}(\mathrm{~mm})$ & $e(\mathrm{~mm})$ & $\delta_{0}$ & \\
\hline $\begin{array}{l}1 \\
2 \\
3 \\
4 \\
5 \\
6 \\
7 \\
7 \\
8\end{array}$ & $\begin{array}{c}2,418 \times 10^{-1} \\
360 \\
964 \\
1,840 \\
3,660 \\
2,290 \\
1,188 \\
2,555\end{array}$ & $\begin{array}{l}1.09 \\
0.17 \\
0.44 \\
0.84 \\
1.66 \\
1.04 \\
0.54 \\
1.16\end{array}$ & $\begin{array}{l}0.1120 \\
0.0070 \\
0.0378 \\
0.0825 \\
0.1690 \\
0.1050 \\
0.0452 \\
0.1177\end{array}$ & $\begin{array}{l}0.00446 \\
0.00850 \\
0.00737 \\
0.00582 \\
0.00737 \\
0.00524 \\
0.01018 \\
0.00524\end{array}$ & $\begin{array}{l}0.0319 \\
0.0020 \\
0.0108 \\
0.0236 \\
0.0483 \\
0.0300 \\
0.0129 \\
0.0336\end{array}$ & $\left\{\begin{array}{l}n E=0.903 \\
P=590 \mathrm{~kg} \\
L=177 \mathrm{~mm} \\
h=7 \mathrm{~mm}\end{array}\right.$ \\
\hline $\begin{array}{l}101 \\
102 \\
103 \\
104 \\
105\end{array}$ & $\begin{array}{l}2,505 \\
2,140 \\
1,818 \\
1,610 \\
1,274\end{array}$ & $\begin{array}{l}1.18 \\
1.01 \\
0.86 \\
0.76 \\
0.60\end{array}$ & $\begin{array}{l}0.1308 \\
0.1130 \\
0.0942 \\
0.0748 \\
0.0575\end{array}$ & $\begin{array}{l}0.00259 \\
0.00120 \\
0.00239 \\
0.00915 \\
0.00868\end{array}$ & $\begin{array}{l}0.0384 \\
0.0332 \\
0.0277 \\
0.0220 \\
0.0169\end{array}$ & \\
\hline $\begin{array}{l}106 \\
107 \\
108 \\
109 \\
110\end{array}$ & $\begin{array}{r}3,600 \\
1,091 \\
820 \\
1,111 \\
2,663\end{array}$ & $\begin{array}{l}1.70 \\
0.52 \\
0.39 \\
0.53 \\
1.26\end{array}$ & $\begin{array}{l}0.1870 \\
0.0486 \\
0.0334 \\
0.0486 \\
0.1348\end{array}$ & $\begin{array}{l}0.00458 \\
0.00812 \\
0.00860 \\
0.00891 \\
0.00637\end{array}$ & $\begin{array}{l}0.0550 \\
0.0143 \\
0.0098 \\
0.0143 \\
0.0396\end{array}$ & $\begin{array}{l}n E=0.898 \\
P=530 \mathrm{~kg}\end{array}$ \\
\hline $\begin{array}{l}111 \\
112 \\
113 \\
114 \\
115\end{array}$ & $\begin{array}{r}1,252 \\
1,472 \\
454 \\
618 \\
1,430\end{array}$ & $\begin{array}{l}0.59 \\
0.69 \\
0.22 \\
0.29 \\
0.67\end{array}$ & $\begin{array}{l}0.0551 \\
0.0700 \\
0.0140 \\
0.0326 \\
0.0721\end{array}$ & $\begin{array}{l}0.00975 \\
0.00716 \\
0.00847 \\
0.00032 \\
0.00938\end{array}$ & $\begin{array}{l}0.0162 \\
0.0206 \\
0.0041 \\
0.0096 \\
0.0212\end{array}$ & $\begin{array}{l}L=177 \mathrm{~mm} \\
h=6.8 \mathrm{~mm}\end{array}$ \\
\hline $\begin{array}{l}116 \\
117 \\
118 \\
119 \\
120\end{array}$ & $\begin{array}{l}1,682 \\
1,333 \\
1,591 \\
1,615 \\
1,660\end{array}$ & $\begin{array}{l}0.79 \\
0.65 \\
0.75 \\
0.76 \\
0.78\end{array}$ & $\begin{array}{l}0.0823 \\
0.0653 \\
0.0823 \\
0.0785 \\
0.0790\end{array}$ & $\begin{array}{l}0.00633 \\
0.00712 \\
0.00231 \\
0.00645 \\
0.00785\end{array}$ & $\begin{array}{l}0.0242 \\
0.0192 \\
0.0242 \\
0.0231 \\
0.0232\end{array}$ & \\
\hline
\end{tabular}
側の歪みの差は，抵抗線歪みゲージにより测定を行な った，荷重は $n_{E}=0.9$ とし，試験片にはアルミニウ

\begin{tabular}{|c|c|c|c|c|c|c|}
\hline No. & $\epsilon_{2}-\epsilon_{1}$ & $\begin{array}{c}w_{a}\left(\frac{L}{2}\right) \\
(\mathrm{mm})\end{array}$ & $a_{0}(\mathrm{~mm})$ & $e(\mathrm{~mm})$ & $s_{0}$ & \\
\hline 31 & $724 \times 10^{-0}$ & 0.33 & 0.0343 & 0.00444 & 0.0099 & \multirow{13}{*}{$\begin{array}{l}n_{E}=0.891 \\
P=590 \mathrm{~kg} \\
L=177 \mathrm{~mm} \\
h=7 \mathrm{~mm}\end{array}$} \\
\hline 52 & 264 & 0. 12 & 0.0143 & 0.00027 & 0.0041 & \\
\hline 33 & 501 & 0.23 & 0.0209 & 0.00550 & 0.0060 & \\
\hline 54 & 1160 & 0.52 & 0.0621 & 0.00169 & 0.0178 & \\
\hline 55 & 201 & 0.09 & 0.0047 & 0.00517 & 0.0013 & \\
\hline 56 & 1370 & 0.62 & 0.0728 & 0.00244 & 0.0208 & \\
\hline 57 & 1382 & 0.62 & 0.0545 & 0.01760 & 0.0156 & \\
\hline 58 & 592 & 0.27 & 0.0183 & 0.01150 & 0.0052 & \\
\hline 59 & 1910 & 0.86 & 0.0725 & 0.02660 & 0.0207 & \\
\hline 60 & 1540 & 0.70 & 0.0811 & 0.00324 & 0.0232 & \\
\hline 61 & 1540 & 0.69 & 0.0680 & 0.01370 & 0.0195 & \\
\hline 62 & 422 & 0.19 & 0.0167 & 0.00533 & 0.0048 & \\
\hline 63 & 2030 & 0.91 & 0.0833 & 0.02310 & 0.0238 & \\
\hline
\end{tabular}
么合金棒（7075-T 628 本，2024-T 413 本）を用い た.

その結果は（7）式および（14）式により第 2 表，第 3表のように求められるが，大体において相当荷重偏 心量eは初期たわみ $\boldsymbol{c}_{0}$ のたかだか $10 \%$ 程度といっ てよくこれまで省略されて来たことは妥当といえよ ろ。しかしながら，初期たわみと荷重偏心は本来，別 のものであるからこれらの分離・決定は柱の軸圧縮 試娩や弾性不安定問題を論ずる際には考虑されなけれ

第2表 $a_{0}$ と $e$ 值 (7075-T6)

第 3 表 $a_{0}$ と $e$ の值 (2024-T4) 
ばならない。

この実験決定において，たわみ曲線を正弦半波1項 で近似している点は $n_{E}$ を1に近くとることて正当化 しており*，試片として用いた矩形中実断面アルミニ ウム合金棒の両端に装着された SK-2 工具鋼製ナ1 フ・エッシ・キャップ（長さ $8.5 \mathrm{~mm}$ )による影稳は 後述の上うに無視出来る**.

試料として用いたアルミニウム合金榛の寸法等はつ ぎのとおりである.

7075-T 6 NOS. $1 \sim 8$

$160 \mathrm{~mm} \times 10 \mathrm{~mm} \times 7 \mathrm{~mm} \quad E=7,280 \mathrm{~kg} / \mathrm{mm}^{2}$ NOS. $101 \sim 120$

$160 \mathrm{~mm} \times 9.8 \mathrm{~mm} \times 6.8 \mathrm{~mm} \quad E=7,275 \mathrm{~kg} / \mathrm{mm}^{2}$ 2024-T 4 NOS. $51 \sim 63$

$160 \mathrm{~mm} \times 10 \mathrm{~mm} \times 7 \mathrm{~mm} \quad E=7,350 \mathrm{~kg} / \mathrm{mm}^{2}$

\section{4. 結}

柱の初期たわみ量と荷重偏心量を実験的に分離・決 定する方法を導いた：実験結果は大多数の場合が荷重 偏心量が小さく，初期たわみ量の $10 \%$ 程度以内に打 さまっていることを示している、これらから本力法が 十分実用性を有することが磼認出来た。

なお。この研究では主として理論解析は林が当た り, 実験の企画および実施, 実験結果の解析ならびに 唡討は小林が担当した。

\section{5. 謝辞}

試験片の入念な製作にあたられた東大航空学科工作 室野村静技官, 試験片素材の提供にあずかった三菱重 工業（株）および古河電気工業（株）に対し潹甚なる 謝意を表するむのである

\section{参考文献}

1) Patel, S.A., Bloom, M., Erickson, B., Chwick, A. and HoFF, N. J.: "Development of Equipment and of Experimental Techniques for Column Creep Tests", NACA TN 3493 (Sept. 1955).

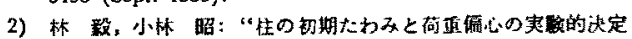

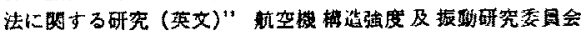
(CAS) 研究報告 No. 8 (1964).

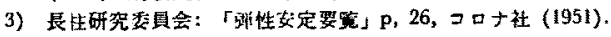

4) KÁRMÁN, T. v, and BloT, M. A.: "Mathematical Methods in Engineering", Chapter 7, Problem 11, McGraw-Hill (1940).

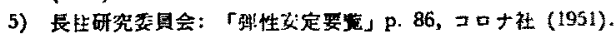

\section{付 1}

㾫心か喠く、初期たわみを有する両端単純支持の柱 が軸压縮をうけるとき，初期たわみを，

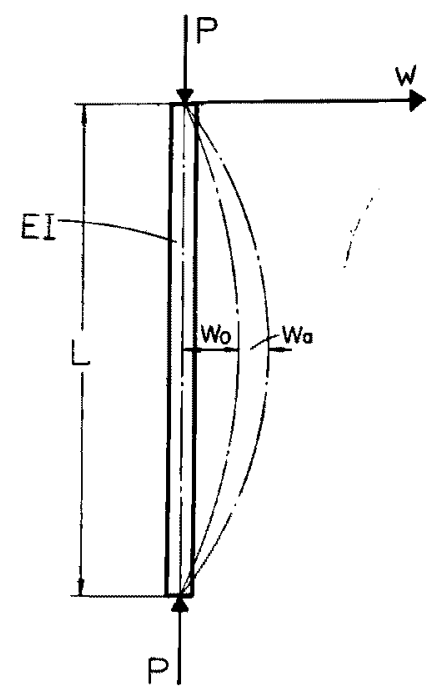

第4図 初期たわみを有する柱の 生縮軸荷量に上るたか子

$$
w_{0}=\sum_{k=1}^{n} b_{k} \sin \frac{k \pi x}{L}
$$

とすると，中心正縮荷重Pによるたわみwは，

$$
E I\left(w^{\prime \prime}-w_{0}^{\prime \prime}\right)=-P w
$$

境界条件： $x=0$ 扰よび $x=L: \quad w=w w^{\prime \prime}=0$

上り,

$$
\begin{aligned}
w= & \sum_{k=1}^{n} \frac{k^{2}}{k^{2}-n_{E}} b_{k} \sin \frac{k \pi x}{L}=\frac{b_{1}}{1-n_{E}} \sin \frac{\pi x}{L} \\
& +\frac{4 b_{2}}{4-n_{E}} \sin \frac{2 \pi x}{L}+\frac{9 b_{s}}{9-n_{E}} \sin \frac{3 \pi x}{L}+\cdots
\end{aligned}
$$

また，付加たわみは，

$$
\begin{aligned}
w_{a}= & w-w_{0}=\frac{n_{E} b_{1}}{1-n_{E}} \sin \frac{\pi x}{L}+\frac{n_{E} b_{2}}{4-n_{E}} \sin \frac{2 \pi x}{L} \\
& +\frac{n_{E}}{9-n_{E}} \sin \frac{3 \pi x}{L}+\cdots
\end{aligned}
$$

とあらわされる. $n_{E}$ が1に近い場合には，たわみw， 付加たわみ $w_{a}$ は $(4 \mathrm{~A}),(5 \mathrm{~A})$ の初項が他項に傮越 してくる゙,

\section{付録 2}

端末の単純支持条件を:出来る限り忠実に保つため に, 試片の両端に銅製ナイフ・エッジキ+ッブを萃 着したがこのために生ずる座届荷重への影響を検討 する(3). 


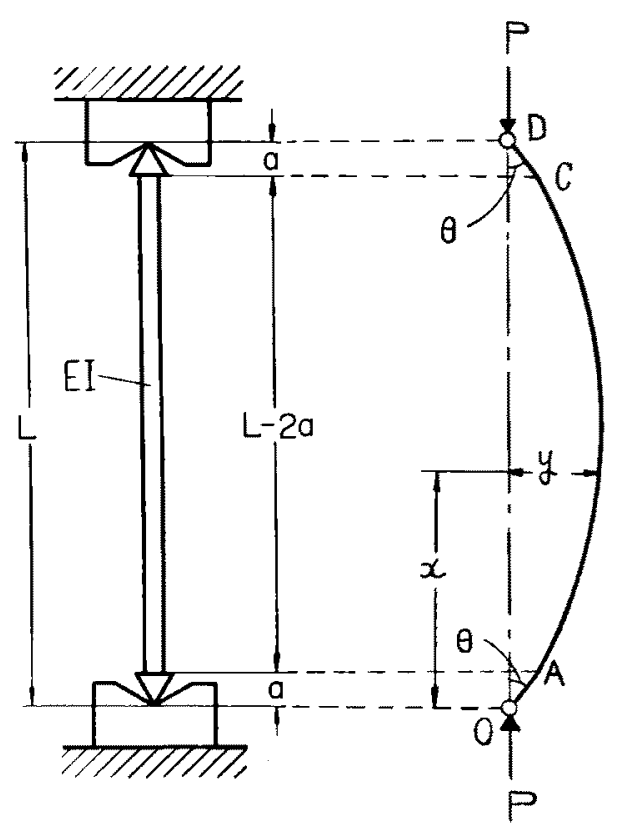

(a)

第 5 图ナ1フ・エッシ・キャッブ

による座届長の悠正

柱は初期たわみる荷重偏心も無いとし、キャップの 断面寸法は武験柱断面寸法に比へて大きくとってある ので，曲げ即性は非常に大て，坐屆たわみ形でのこの 部分 $O A, C D$ は直程と考えてよい. 寸なわり，用体 としてよい.

今, $a \leqq x \leqq L / 2$ では,

$$
E I y^{\prime \prime}+P y=0
$$

境界条件: $y(a)=a \theta, y^{\prime}(L / 2)=0$

また， $x=a$ ては，

$$
\theta=\frac{d y}{d x}=\frac{y}{a}
$$

てあり, (1B), (2B) および (3B) より

$$
\begin{aligned}
y(x) & =A \sin \lambda x+B \cos \lambda x \\
\lambda^{2} & =\frac{P}{E I}
\end{aligned}
$$

が得られ，(4B) を(2B),(3B) に代入して $\theta$ を消 去すると、幽屈案件式

$$
\cot \frac{\lambda}{2}(L-2 a)=a \lambda
$$

+5K,

$$
\tan \left[\frac{\pi}{2}-\frac{\lambda L}{2}\left(1-\frac{2 a}{L}\right)\right]=\frac{\lambda L}{2} \frac{2 a}{L}
$$

便富上，

$$
\left.\begin{array}{l}
\frac{\lambda L}{2}=\frac{L}{2} \sqrt{\frac{P}{E I}}=\xi \\
\frac{2 a}{L}=\eta
\end{array}\right\}
$$

とすれば (6B) は

$$
\tan \left[\frac{\pi}{2}-\xi(1-\eta)\right]=\xi \eta
$$

となる。

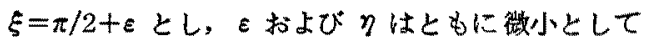
（8B）を展開し，第 1 䜣似をとると，

$$
P=\frac{\pi^{2} E I}{L^{2}}\left[1+\frac{\pi^{2}}{6}\left(\frac{2 a}{L}\right)^{3}\right]
$$

を座屈荷重として得る、括弧内第 2 項がキャップの影 整を示すか，本実験で $a=8.5 \mathrm{~mm}, L=177 \mathrm{~mm}$ て あり

$$
\frac{\pi^{2}}{6}\left(\frac{2 a}{L}\right)^{3}=\frac{\pi^{2}}{6}\left(\frac{17}{177}\right)^{3}=1.46 \times 10^{-8}
$$

となって $L=177 \mathrm{~mm}$ 全長にわたって一様な $E I$ を有 するとしたときの座届荷重に与えるキャップの影䛚は $0.15 \%$ であって無視出来ることが分かる。 